\title{
Isolated pituitary metastasis from renal cell carcinoma in a horseshoe kidney
}

\author{
Kay K Win*1, Nissa Blocher ${ }^{1}$, William Tester ${ }^{2}$, Serge Ginzburg ${ }^{3}$, Lauren Pomo ${ }^{4}$ \\ ${ }^{1}$ Endocrinology, Einstein Medical Center, Philadelphia, United States \\ ${ }^{2}$ Hematology and Oncology, Einstein Medical Center, Philadelphia, United States \\ ${ }^{3}$ Urology, Einstein Medical Center, Philadelphia, United States \\ ${ }^{4}$ Pathology and Laboratory Medicine, Einstein Medical Center, Philadelphia, United States
}

Received: November 5, 2017

Accepted: January 4, 2018

Online Published: January 11, 2018

DOI: $10.5430 /$ jst.v8n1p37

URL: https://doi.org/10.5430/jst.v8n1p37

\begin{abstract}
Objective: To describe a patient with isolated symptomatic pituitary metastasis from Renal Cell Carcinoma (RCC) in a horseshoe kidney.

Case report: We report a case of 56-year-old man with RCC of a horseshoe kidney with symptomatic isolated pituitary gland metastasis. He initially presented to us for evaluation of a sellar mass. He complained of fatigue, 50-pound weight loss, anorexia, constipation and nonspecific abdominal pain for 4 months. CT head showed $2.6 \mathrm{~cm} \times 1.8 \mathrm{~cm} \times 2.5 \mathrm{~cm}$ sellar mass likely with bilateral cavernous sinus extension. Pituitary function evaluation revealed panhypopituitarism. CT abdomen/pelvis for the evaluation of abdominal pain showed $12.1 \mathrm{~cm}$ solid mass in the right renal moiety of a horseshoe kidney. Hydrocortisone and levothyroxine therapy led to cessation of weight loss, but unmasked diabetes insipidus requiring desmopressin therapy. Right heminephrectomy confirmed RCC. Soon after he complained of progressively worsening headache and visual disturbance. Histopathology from urgent trans-sphenoidal hypophysectomy revealed RCC. The patient began post-surgical radiotherapy, but eventually he declined further treatments. In the end, he was placed on hospice where he passed away.

Conclusion: Symptomatic pituitary metastasis from RCC are rare and most of those occur in the setting of diffuse metastatic disease. They typically mimic signs and symptoms of non-functioning macroadenomas. They can be synchronous, metachronous or even the presenting lesion of the primary tumor. A pituitary mass in the setting of malignancy should raise suspicion for metastatic disease even though it is extremely rare.
\end{abstract}

Key Words: Pituitary metastasis, Renal cell carcinoma, Panhypopituitarism, Sellar mass

\section{INTRODUCTION}

Pituitary Metastases from Renal Cell Carcinoma (RCC) are extremely rare. Less than $1 \%$ of all resected pituitary lesions are found to be metastases, with RCC accounting for only $2.6 \%$ of these cases. ${ }^{[1]}$ In pituitary metastases cases, breast is the most common primary carcinoma in females and lung in males. ${ }^{[2]}$ Only an estimated $7 \%$ of all pituitary metastases are symptomatic. ${ }^{[3-5]}$ We could find only 31 cases of symptomatic pituitary metastasis from RCC reported in the literature, ${ }^{[6-8]}$ and most of these cases described diffuse metastatic disease. Isolated symptomatic pituitary metastasis from RCC, therefore, is extremely rare.

\footnotetext{
*Correspondence: Kay K Win, MD; Email: winkay00@einstein.edu; Address: Medical Arts Building, 50 Township Line Road, Suite G 01, Elkins Park, PA, 19027, United States.
} 


\section{Case presentation}

A 56-year-old African American man presented for the evaluation of a sellar mass. Over 4 months before presentation, he had developed fatigue, 50-pound weight loss, anorexia, constipation, and nonspecific abdominal pain. CT head demonstrated a $2.6 \mathrm{~cm} \times 1.8 \mathrm{~cm} \times 2.5 \mathrm{~cm}$ sellar mass. Unfortunately, magnetic resonance imaging (MRI) was contraindicated due to retained bullet fragments in his left upper chest. The CT, however, was able to show that there was no suprasellar extension at this time, likely bilateral cavernous sinus involvement, heterogeneous enhancement of the mass, and bony destruction of the hypophyseal fossa that appeared to be recent based on lack of cortical thickening at the sites of destruction (see Figure 1, A1-A2). Pituitary function evaluation revealed panhypopituitarism (see Table 1). TSH and total testosterone levels were normal about one year prior. On presentation, he had no visual complaints and visual fields were normal on exam. He denied polyuria and polydipsia. Hydrocortisone and levothyroxine therapy led to cessation of weight loss, but unmasked severe, symptomatic diabetes insipidus requiring desmopressin therapy.
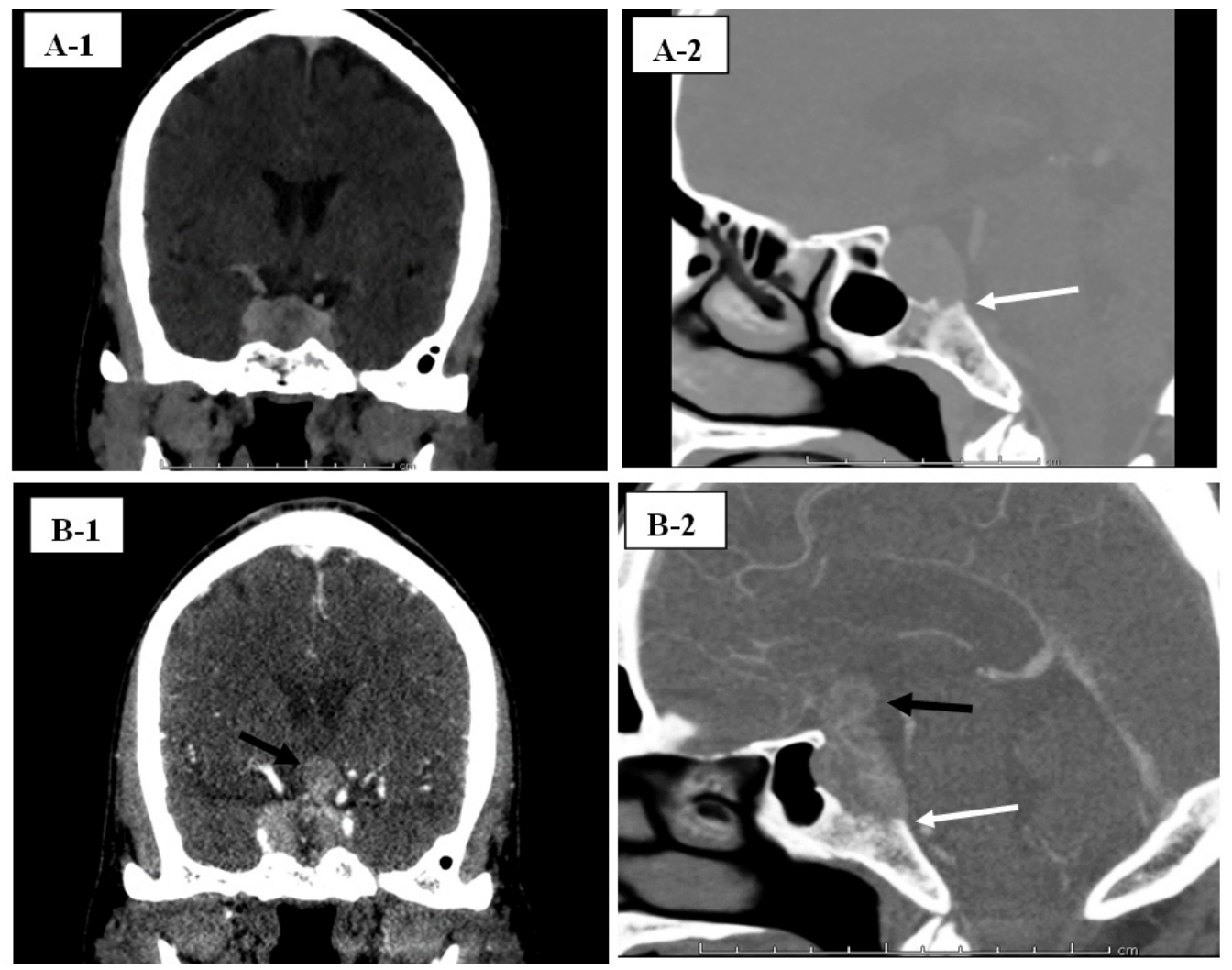

Figure 1. (A) At presentation: CT head (A-1) Coronal and (A-2) Sagittal images showing a $2.6 \mathrm{~cm} \times 1.8 \mathrm{~cm} \times 2.5 \mathrm{~cm}$ sellar mass likely with bilateral cavernous sinus extension. (B) Five months later: CT angiogram (B-1) Coronal and (B-2) Sagittal images showing the mass at $3.6 \mathrm{~cm} \times 2.2 \mathrm{~cm} \times 2.5 \mathrm{~cm}$ with new suprasellar extension (black arrow). All images demonstrate the heterogeneity of the mass. Both sagittal images show boney destruction (white arrow).

Table 1. Results of hormonal evaluation

\begin{tabular}{llll}
\hline Hormone & 1-year prior & Presentation & Normal range \\
\hline TSH $(\mathrm{mIU} / \mathrm{L})$ & 1.72 & $0.07 \mathrm{~L}$ & $0.4-4.5$ \\
Free T4 $(\mathrm{ng} / \mathrm{dl})$ & & $0.6 \mathrm{~L}$ & $0.8-1.8$ \\
FSH $(\mathrm{mIU} / \mathrm{ml})$ & $1.5 \mathrm{~L}$ & $1.6-8$ \\
$\mathrm{LH}(\mathrm{mIU} / \mathrm{ml})$ & & $0.2 \mathrm{~L}$ & $1.5-9.3$ \\
$\mathrm{AM} \mathrm{cortisol}(\mu \mathrm{g} / \mathrm{dl})$ & & $3.3 \mathrm{~L}$ & $4-22$ \\
Prolactin $(\mathrm{ng} / \mathrm{ml})$ & & $78.8 \mathrm{H}$ & $2.0-18$ \\
Testosterone $(\mathrm{ng} / \mathrm{dl})$ & $290(1 \mathrm{pm})$ & Not done & $250-1,100$ \\
\hline
\end{tabular}

Note TSH = thyroid stimulating hormone; $\mathrm{T} 4$ = thyroxine; FSH = follicular stimulating hormone; $\mathrm{LH}=$ luteinizing hormone 


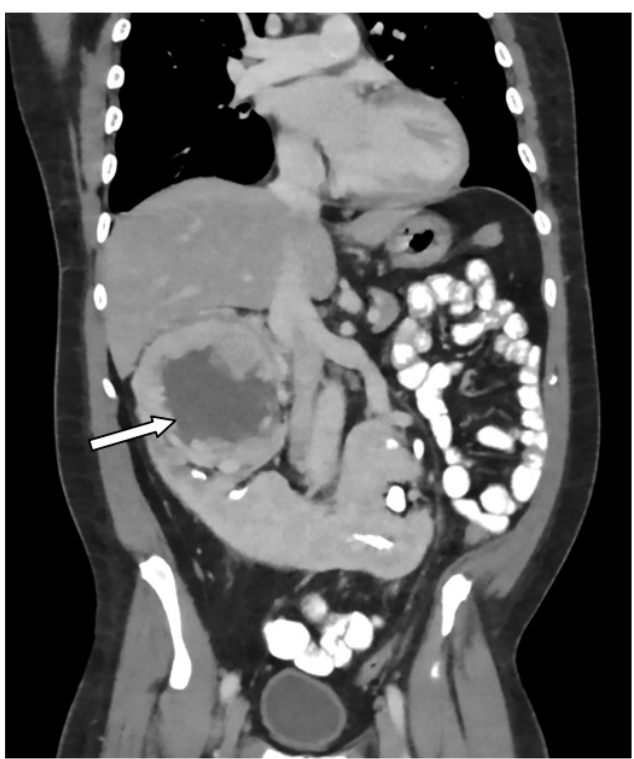

Figure 2. CT abdomen showing the $12.1 \mathrm{~cm}$ mass (white arrow) arising from the right renal moiety of a horseshoe kidney

Axial imaging of the abdomen was performed for abdominal pain after the sellar mass was found and before we met him in endocrinology clinic. It found a $12.1 \mathrm{~cm}$ mass arising from the right renal moiety of a horseshoe kidney (see Figure 2) and radiologic staging including CT thorax disclosed no other metastases apart from small mediastinal lymph nodes. After his pituitary hormones were replaced, he underwent successful open, adrenal-sparing heminephrectomy. Histopathology revealed clear cell RCC, Fuhrman grade 2, confined to the kidney, with negative surgical margins, pT2a. CT head at that time found no significant change in the sellar mass. One month later, however, the patient called to complain of progressively worsening headache and visual disturbance such that he could no longer drive. Bitemporal hemianopsia was clearly evident on physical exam. Urgent repeat CT head found that the sellar mass was now $3.6 \mathrm{~cm} \times 2.2 \mathrm{~cm} \times 2.5 \mathrm{~cm}$ and included a $1.0 \mathrm{~cm}$ suprasellar extension that abutted the optic chiasm (see Figure 1, B1-B2). Urgent trans-sphenoidal hypophysectomy by endoscopic approach to debulk the mass was performed. Histopathology confirmed neoplastic cells consistent with RCC with round to ovoid nuclei, prominent nucleoli and variable clear and eosinophilic cytoplasm (see Figure 3A). Immunohistochemical study showed the tumor was positive for vimentin, RCC and CD 10, which is consistent with RCC (see Figure 3, B-D). Subsequent imaging studies including CT head, chest and abdomen found no evidence of local recurrent disease, additional metastases or lymphadenopathy. To address the known residual mass, the patient was strongly encouraged to proceed with further sur- gical and/or radiotherapy intervention, but he withdrew into depression and declined treatment. Less than two months later, he was hospitalized for altered mental status and agreed to have craniotomy for resection of the suprasellar component of the mass to decompress the progressively worsening optic nerve involvement. His vision improved significantly after the operation. Post-surgical pituitary fractionated radiation therapy was initiated, but he stopped coming in for treatments or any appointments. Three months later, he presented to another hospital with severe altered mental status and functional decline. He was eventually discharged on home hospice where he passed away.

\section{DisCUSSION}

Pituitary metastasis is rare and has been described in only $1 \%-4 \%$ of cases dying from systemic cancer in numerous autopsy series reports. ${ }^{[9-11]}$ Breast and lung cancers are the most common primary source for pituitary metastasis, making up $37.2 \%$ and $24.2 \%$ of cases respectively. The next most common primary sites are prostate $(5 \%)$ and kidney, specifically renal cell carcinoma $(2.6 \%)$ respectively. ${ }^{[2,10]}$

Metastases to the pituitary gland tend to involve the posterior lobe and the infundibulum more frequently than the anterior lobe. Presumably this is because the posterior pituitary lobe receives blood supply from the systemic circulation while the anterior pituitary lobe is supplied by hypophyseal portal vasculature. ${ }^{[12]}$ Some reports suggested that certain malignant diseases such as breast cancer may have an increased affinity for the anterior lobe due to a nascent hormonal attraction. ${ }^{[2]}$

Majority of the patients with pituitary metastases are asymptomatic. In an autopsy review of 88 cases, Teears found that only $7 \%$ of patient had been symptomatic. ${ }^{[13]}$ As for symptomatic pituitary metastasis from RCC, we could find only 31 cases reported in the literature. Most of those occurred in the setting of diffuse metastatic disease.

The most common clinical manifestation of pituitary metastasis from any primary is diabetes insipidus (DI), reported in up to $70 \%$ of the cases. Anterior pituitary hormone deficiencies are reported in only $15 \%-20 \%$ of the cases. ${ }^{[3,12]}$ However, anterior pituitary hormonal deficiencies are probably underreported since symptoms may be masked by or assumed to be caused by those of the primary malignancy. ${ }^{[2]}$ Hyperprolactinemia caused by stalk compression has been reported in approximately $6 \%$ of patients. ${ }^{[1]}$ RCC seems to operate uniquely from pituitary metastases of other malignancies in that anterior hypopituitarism is much more common $(88 \%$ of reported cases) than DI (only $30 \%$ of reported cases). ${ }^{[7]}$ Our patient was symptomatic and exhibited both anterior hormone deficiencies and DI. 

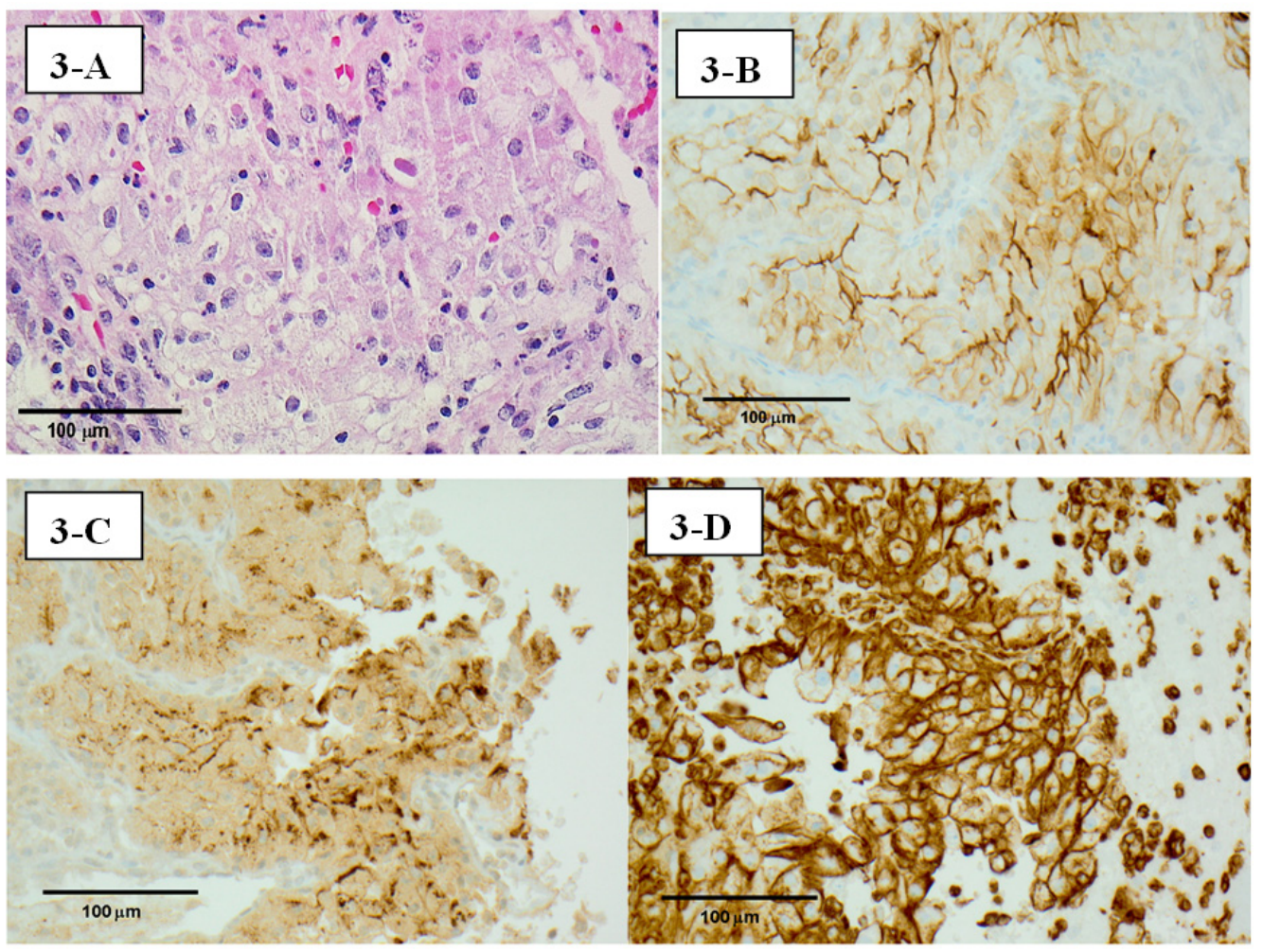

Figure 3. (A) Hematoxylin and eosin stain $(40 \times)$ of the pituitary tumor showing neoplastic cells consistent with RCC with round to ovoid nuclei, prominent nucleoli, and variable clear and eosinophilic cytoplasm. Immunohistochemistry study showed tumor cells positive for $(B)$ CD10 $(40 \times)$ shows the characteristic tumor cell membranous expression, $(C)$ RCC $(40$ $\times$ ) shows granular cytoplasmic and membranous expression in the tumor cells and (D) Vimentin $(40 \times)$ strongly highlights the tumor cells membranes.

Visual field deficits were found in $82 \%$ of RCC metastases cases, which is more common than other primaries and may be due to an invasive growth pattern of the tumor. ${ }^{[7]}$ Compression of cranial nerve II at the optic chiasm causing bitemporal hemianopsia $(27.9 \%)$ is the most common visual defect in all pituitary metastases. ${ }^{[8]}$

There were many clues to our patient's diagnosis on presentation. The onset of his symptoms was much more rapid compared with that typical of pituitary macroadenoma. Despite normal TSH and testosterone one year prior, by presentation he had severe anterior pituitary deficiencies, DI, which was noticed once unmasked by glucocorticoid replacement, and hyperprolactinemia from stalk compression. Visual field impairment with bitemporal hemianopsia occurred within a few months of presentation as the mass rapidly enlarged.

MRI is the modality of choice for assessment of the pituitary region. Regardless of modality, the radiological appearance of a pituitary metastasis is usually indistinguishable from an adenoma. In Komninos' review of 70 cases, pituitary metastases were enhancing, homogeneously or inhomogeneously, in more than $50 \%$ of cases. $20 \%$ of cases showed sellar floor erosion. However, both of these findings are not uncommon in adenomas and thus non-specific. No other imaging characteristic was shared by more than $20 \%$ of case. ${ }^{[1]}$

There are no standardized treatment guidelines for pituitary metastases. Overall survival among patients with a recognized pituitary metastasis from any primary is poor, with mean survival rates reported to range between 6 and 22 months. ${ }^{[3]}$ The management of such patients is mainly palliative and should be directed at minimizing morbidity from symptomatic lesions and maximizing the remaining quality of life. Options for treatment include trans-sphenoidal surgery (TSS), radiotherapy, and chemotherapy. Surgical debulking is mainly for the relief of pain and visual compromise. Total resection is often impossible due to the significant vascularity of these tumors, local invasion into the surrounding bone and cavernous sinus, and infiltration of the hypothalamus and optic nerves. ${ }^{[2,6]}$ Hypopituitarism and DI are not likely to respond to surgical therapy and must be medically managed. Operative case series have not found any significant survival benefits from tumor resection, though the patient's quality of life may be improved. ${ }^{[3,14]}$ 
Radiotherapy can be given as fractionated, external radiation or stereotactic radio-surgery. Radiotherapy can be used as primary therapy in patients who are not candidates for surgery or as an adjuvant therapy after trans-sphenoidal surgery. ${ }^{[14]}$ The usefulness of chemotherapeutic agents varies by primary tumor type. Thyroxine kinase inhibitors (Sorafenib and sunitinib) have been reported to use as palliative therapy to control the growth of RCC metastases in a few cases. ${ }^{[7]}$ Yang proposed that sole treatment with targeted chemotherapeutic drugs like sorafenib is inadequate for control of brain metastases, including RCC metastasis. ${ }^{[15]}$ However, in one case report, $\mathrm{RCC}$ with metastases that included the pituitary gland, lung, and bone had a complete response to treatment with sunitinib and bevacizumab without surgery or radiotherapy. ${ }^{[16]}$

Most masses found in the pituitary gland are not metastases. Our case and review of the literature supports the importance of consideration of metastasis in cases with certain clinical and radiological conditions. In our case, initial radiology opinion was that the sellar mass found on CT was statistically more likely to be a macroadenoma than a metastasis.
However, there were specific clues to suggest otherwise. The patient had a known primary tumor. He presented with rapid onset of hypopituitarism. His mass was enhancing and showed evidence of rapid local boney destruction of the sellar floor. He developed visual impairment rapidly and subsequent imaging revealed the rapid tumor growth. Our case supports previous reports that patients with pituitary metastasis from RCC specifically present more commonly with anterior hypopituitarism than isolated DI. Treatment with TSS, radiation therapy, or chemotherapy may control or slow disease progression, but such intervention must be considered urgently as tumors can progress rapidly. Despite surgical debulking, our patient survived only 14 months after presentation. This case illustrates the importance of considering metastatic disease among the causes of a sellar mass, especially when a patient is known to have metastatic cancer, or when the radiologic appearance suggests an aggressive tumor, as described above.

\section{CONFLICTS OF INTEREST Disclosure}

The authors declare that there is no conflict of interest statement.

\section{REFERENCES}

[1] Komninos J, Vlassopoulou V, Protopapa D, et al, Tumors metastatic to the pituitary gland: case report and literature review. J Clin Endocrinol Metab. 2004 Feb; 89(2): 574-80. PMid:14764764 https : //doi.org/10.1210/jc.2003-030395

[2] Fassett DR, Couldwell WT, et al. Metastases to the pituitary gland. Neurosurg Focus. 2004; 16: E8. PMid:15191337 https://doi .or $\mathrm{g} / 10.3171 /$ foc 2004.16 .4 .9

[3] Morita A, Meyer FB, Laws ER Jr, et al. Symptomatic pituitary metastases. J Neurosurg. 1998 Jul; 89(1): 69-73. PMid:9647174 https://doi.org/10.3171/jns.1998.89.1.0069

[4] Koshiyama H, Ohgaki K, Hida S, et al. Metastasis renal cell carcinoma to the pituitary gland presenting with hypopituitarism. J Endocrinol Invest. 1992; 15: 677-81. PMid:1479150 https://doi. org/10.1007/BF03345815

[5] Weber J, Gassel AM, Hoch A, et al. Concomitant renal cell carcinoma with pituitary adenoma. Acta Neurochir (Wien). 2003; 145: 227-31. PMid:12632120 https://doi.org/10.1007/s00701-0 02-1060-0

[6] Murrone D, Abbate FA, Paulis DD, et al. Pituitary gland metastases from renal cell carcinoma: A case report and literature update. Integr Cancer Sci Therap; 2015.

[7] Gopan T, Toms SA, Prayson RA, et al. Symptomatic pituitary metastases from renal cell carcinoma. Pituitary. 2007; 10: 251-9. PMid:17541748 https://doi .org/10.1007/s11102-007-004 7-5

[8] Wendel C, Campitiello M, Plastino F, et al. Pituitary Metastasis from Renal Cell Carcinoma. Description of a Case Report, Am J Case Rep. 2017; 18: 7-11. PMid:28044054 https://doi.org/10.12659/A JCR. 901032

Published by Sciedu Press
[9] Kovacs K. Metastatic Cancer of the Pituitary Gland. Oncology. 1973; 27: 533-42. PMid:4355105 https://doi.org/10.1159/000224 763

[10] He W, Chen F, Dalm B, et al. Metastatic involvement of the pituitary gland: a systematic review with pooled individual patient data analysis. Pituitary. 2014; 18(1): 159-68. PMid:24445565 https: //doi.org/10.1007/s11102-014-0552-2

[11] Kramer CK, Ferreira N, Silveiro SP, et al. Pituitary gland metastasis from renal cell carcinoma presented as a non-functioning macroadenoma. Arq Bras Endocrinol Metabol. 2010; 54(5): 498501. PMid:20694412 https://doi.org/10.1590/S0004-273 02010000500011

[12] McCormick PC, Post KD, Kandji Ad, et al. Metastatic carcinoma to the pituitary gland. Br J Neurosurg. 1989; 3(1): 71-9. PMid:2789715 https://doi .org/10.3109/02688698909001028

[13] Teears R, Silverman EM. Clinicopathological review of 88 cases of carcinoma metastatic to pituitary gland. Cancer. 1975; 36: 21620. https://doi.org/10.1002/1097-0142(197507)36:1<21 $6:$ : AID-CNCR2820360123>3.0.CD;2-E

[14] Yokoyama T, Yoshino A, Katayama Y, et al, Metastatic pituitary tumor from renal cell carcinoma treated by fractionated stereotactic radiotherapy-case report. Neurol Med Chir (Tokyo). 2004 Jan; 44(1): 47-52. https://doi.org/10.2176/nmc. 44.47

[15] Yang L, Yu SY, Hu GY, et al. Pituitary metastasis from a renal cell carcinoma progressed after sorafenib treatment. Chin J Cancer. 2013 Jun; 32(6): 353-6. PMid:23237217 https://doi .org/10.5732/ cjc.012.10184

[16] Payandeh M, Sadeghi M, Sadeghi E, et al. The Complete Response to Targeted Drugs Without Surgery or Radiotherapy: A Case of Pituitary Metastasis from Renal Cell Carcinoma. Acta Med Iran. 2016 Sep; 54(9): 617-9. PMid:27832697 